\title{
The effects of in ovo feeding of glutamine in broiler breeder eggs on hatchability, development of the gastrointestinal tract, growth performance and carcass characteristics of broiler chickens
}

\author{
Mehdi Salmanzadeh, Yahya Ebrahimnezhad, Habib Aghdam Shahryar, and \\ Jamshid Ghiasi Ghaleh-Kandi \\ Departments of Animal Science, Shabestar branch, Islamic Azad University, Shabestar, Iran \\ Correspondence to: Yahya Ebrahimnezhad (ebrahimnezhad@gmail.com)
}

Received: 27 February 2016 - Revised: 30 April 2016 - Accepted: 17 May 2016 - Published: 31 May 2016

\begin{abstract}
The aim of the present study was to investigate the effect of in ovo feeding (IOF) of glutamine on hatchability, development of the gastrointestinal tract, growth performance and carcass characteristics of broiler chickens. Fertilized eggs were subjected to injections with glutamine (Gln) (10, 20, 30, 40 or 50 mg dissolved in $0.5 \mathrm{~mL}$ of dionized water) on day 7 of incubation. Hatchability, growth performance, carcass characteristics (carcass weight and relative weights of breast, thigh, heart, liver, gizzard, abdominal fat, intestine, pancreas and spleen) and jejunal morphometry (measurement of villus height and width and crypt depth) were determined during the experiment. The weight of newly hatched chickens was significantly greater in groups with Gln injection than in control and sham groups. But IOF caused lower hatchability than in the control group (noninjected eggs) $(p<0.05)$. Chickens from IOF of Gln showed better weight gain and feed conversion ratio $(0-$ 42 days of age), when compared to chickens hatched from control and sham groups. The IOF of Gln significantly increased villus height, villus width and crypt depth at hatch period and villus height at 42 days of age. In addition, carcass weights and relative weights of breast, thigh and gizzard were also markedly increased in chickens treated in ovo with Gln; whereas heart, liver, abdominal fat, intestine, pancreas and spleen were not significantly altered at the end of the experimental period. These data suggest that the IOF of Gln may improve jejunum development, leading to an increased nutrient assimilation and consequently to greater performance in broiler chickens.
\end{abstract}

\section{Introduction}

In ovo feeding (IOF) is a method of supplementing exogenous nutrients into amnion of the avian embryo (Uni and Ferket, 2003), which can improve the performance of chicks from injected eggs (Salmanzadeh, 2011; Salmanzadeh et al., 2012; Dong et al., 2013). Previous studies have been conducted to assess nutrients for in ovo injection in broiler embryos, such as carbohydrates (Tako et al., 2004a; Uni et al., 2005; Smirnov et al., 2006), amino acids (Al-Murrani, 1982; Ohta et al., 1999, 2001, 2004), vitamins (Nowaczewski et al., 2012) and minerals (Tako et al., 2004b). However, there are few studies on IOF of Gln in broiler breeder hen eggs.
Glutamine (Gln) is the principle metabolic fuel for development of the gastrointestinal tract (Andrew and Griffiths, 2002), and is considered as a non-essential amino acid since most animal cells can synthesize it, which can play an important role in the synthesis of many biologically important molecules (Souba, 1993). These results are in agreement with the findings of Samli et al. (2007), who reported that Gln is an important amino acid for utilization as an energy source for the development of the gastrointestinal tract and stimulates intestinal cell proliferation, which leads to increasing the absorptive source of the gastrointestinal mucosa and consequently the access to nutrients. In parallel, previous experiments, showed that supplementing the diet with 
Table 1. Composition and calculated contents of nutrients of broiler diet.

\begin{tabular}{|c|c|c|c|}
\hline \multirow[t]{2}{*}{ Item } & \multicolumn{3}{|c|}{ Diet } \\
\hline & Starter $0-10$ days & Grower $11-26$ days & Finisher 27-42 days \\
\hline \multicolumn{4}{|l|}{ Ingredient $(\%)$} \\
\hline Corn & 60.36 & 65.44 & 66.8 \\
\hline Soybean meal (44\% CP) & 34.12 & 28.62 & 26.33 \\
\hline Vegetable fat & 1.23 & 1.74 & 2.84 \\
\hline Dicalcium phosphate & 1.83 & 1.8 & 1.67 \\
\hline Oyster sell-ground & 1.22 & 1.19 & 1.13 \\
\hline Salt & 0.35 & 0.3 & 0.3 \\
\hline Sodium bicarbonate & 0.11 & 0.07 & 0.07 \\
\hline Vitamin premix ${ }^{1}$ & 0.25 & 0.25 & 0.25 \\
\hline Trace mineral premix ${ }^{2}$ & 0.25 & 0.25 & 0.25 \\
\hline DL-Met & 0.17 & 0.18 & 0.18 \\
\hline L-Lys & 0.11 & 0.16 & 0.18 \\
\hline \multicolumn{4}{|l|}{ Calculated analysis } \\
\hline $\operatorname{ME}\left(\mathrm{kcal} \mathrm{kg}^{-1}\right)$ & 2894 & 2987 & 3176 \\
\hline $\mathrm{CP}(\%)$ & 20.3 & 18.3 & 18 \\
\hline $\mathrm{Ca}(\%)$ & 1 & 0.96 & 0.9 \\
\hline Available P (\%) & 0.50 & 0.48 & 0.45 \\
\hline $\operatorname{Met}(\%)$ & 0.46 & 0.44 & 0.43 \\
\hline Met + cystine $(\%)$ & 0.89 & 0.84 & 0.82 \\
\hline Lys (\%) & 1.20 & 1.10 & 1.05 \\
\hline
\end{tabular}

Gln increased intestinal villus height and consequently, improved growth performance in broilers (Bartell and Batal, 2007; Yi et al., 2005; Jazideh et al., 2014), turkey poults (Yi et al., 2001; Salmanzadeh and Shahryar, 2013a) quails (Salmanzadeh and Shahryar, 2013b) and weanling pigs (Kitt et al., 2002), compared to control groups. Chen et al. (2009) demonstrated that, body weights measured at the 7-days old post-hatching were significantly modified in ducks treated in ovo injection with Gln.

All these beneficial actions of Gln in particular, make it an amino acid deserving of scientific and technical attention.

It was hypothesized that IOF of Gln can improve the development of the gastrointestinal tract, by increasing the absorptive surface area that consequently promotes the nutrient assimilation and improves growth performance in broiler chickens. Thus, the aims of this research were to investigate the effects of IOF of Gln in broiler breeder eggs in hatchability, development of the gastrointestinal tract, growth performance and carcass characteristics of broiler chickens.

\section{Material and method}

\subsection{Incubation and in ovo feeding}

Hatching eggs of approximately similar weights $(65 \pm 1 \mathrm{~g})$ were obtained from broiler breeder strain (Cobb 500) at 42 weeks of age. A total of 1400 fertile eggs were numbered, fumigated with formaldehyde gas, and incubated at $37.7^{\circ} \mathrm{C}$ and $64 \% \mathrm{RH}$. On the 6th day of incubation, the eggs were candled, and the infertile ones or those containing only dead embryos were removed. On the 7th day, fertile eggs were randomly allotted to seven treatments with four replicate per treatment and 50 eggs per replicate. Eggs were injected with Gln $(10,20,30,40$, and $50 \mathrm{mg}$, respectively) dissolved in $0.5 \mathrm{~mL}$ of deionized water whereas in the sham group, eggs were only treated with deionized water $(0.5 \mathrm{~mL})$ and those of the control group received no injection.

Before injection, each egg was candled to identify the location of the future injection. The injection hold area was cleaned with ethyl alcohol (70\%) and the blunt end was punched using a 22 gauge needle. Then, the solutions were injected into albumen $\left(0.5 \mathrm{~mL} \mathrm{egg}^{-1}\right)$ using another disposable syringe equipped with a 22 gauge needle to a depth of about $13 \mathrm{~mm}$ (Salmanzadeh et al., 2012). After injection, the 
eggs were sealed with cellophane tape, and transferred to the incubator. Control eggs were removed from the incubator together with the treated groups, and kept in the same environment. The group of eggs designated as sham-injected controls were injected with $0.5 \mathrm{~mL}$ of deionized water. Deionized water injections were included as sham controls primarily to rule out a possible negative response caused by the stress of injection and handling. L-Glutamine was supplied from Sigma ${ }^{\circledR}$ Co (anhydrous $\geq 99 \%$, CAS Number: 56-859). All of the treatment solutions were prepared in autoclaved water.

\subsection{Birds and data collection}

After hatching, chickens were transferred to an experimental house and reared for 42 days with the same ration according to the requirements of broiler as recommended by the catalog of Cobb 500 broilers (Table 1). Each chicken according to the treatment group was identified by the neck tag and recorded. All chickens and treatments were randomly assigned to 1 of 28 pens. Each open was provided with water and an individual feeder. Room temperature was maintained at $32^{\circ} \mathrm{C}$ from 0 to 4 and then gradually reduced from 32 to $21^{\circ} \mathrm{C}$. All experimental protocols and procedures were approved by the institutional Animal Care of Iran.

Upon hatching, the number of hatchlings was determined to calculate the hatchability of fertile eggs. The weight of newly hatched chickens was determined by weighing all chickens hatched one by one. In each pen, bird body weight and food intake were recorded on days 1, 10, 26, and 42 posthatching and thereafter mean body weight gain, food intake, and food conversion ratio were calculated for each pen (replicate) between 0 and 10, 11 and 26, 27 and 42, and 1 and 42 days. In each time period, body weight gain was calculated and expressed as grams per bird. Food intake ( $\mathrm{g}$ of food intake/bird) over the entire grow-out period was calculated by totalling food consumption in each time interval between each bird sampling. Food conversion ratio ( $\mathrm{g}$ of food intake/g of body weight gain) was calculated by dividing total food intake by total weight gain in each pen.

\subsection{Morphometric indices of the jejunum}

At hatching and 10 days of age, eight birds from pretreatment were euthanized by cervical dislocation. Then, gastrointestinal tract was carefully excised. One cross-section for jejunum was fixed with formalin solution and was prepared using standard paraffin embedding procedures by sectioning at $5 \mathrm{~mm}$ thickness, and staining with hematoxylin and eosin. Villus height (VH), villus width (VW) and crypt depth (CD) were determined using an image processing and analyzing system (Image Pro plus) and were expressed as micrometers (Touchette et al., 2002).
Table 2. Effects of IOF of Gln on weight and hatchability in newly hatched chickens.

\begin{tabular}{lrr}
\hline Groups & Hatchability $(\%)$ & Weight $(\mathrm{g})$ \\
\hline Control & $89.58^{\mathrm{a}}$ & $43.41^{\mathrm{e}}$ \\
Sham group & $72.22^{\mathrm{c}}$ & $43.31^{\mathrm{e}}$ \\
Gln $^{1} 10 \mathrm{mg}$ & $75.69^{\mathrm{bc}}$ & $43.82^{\mathrm{cd}}$ \\
Gln 20 mg & $75.00^{\mathrm{bc}}$ & $43.71^{\mathrm{d}}$ \\
Gln 30 mg & $76.38^{\mathrm{bc}}$ & $44.09^{\mathrm{ab}}$ \\
Gln 40 mg & $79.16^{\mathrm{b}}$ & $43.93^{\mathrm{bc}}$ \\
Gln 50 mg & $77.77^{\mathrm{bc}}$ & $44.21^{\mathrm{a}}$ \\
SEM & 1.75 & 0.05 \\
$P$ Value & 0.0001 & 0.0001 \\
\hline
\end{tabular}

${ }^{1} \mathrm{Gln}=$ Glutamine; ${ }^{\mathrm{a}-\mathrm{e}}$ averages in a column with different superscript letters are significantly different.

Table 3. Effects of IOF of Gln on body weight gain (BWG), food intake (FI) and feed conversion ratio (FCR) of broilers to 1-10 days of age.

\begin{tabular}{lrrr}
\hline \multirow{2}{*}{ Groups } & \multicolumn{3}{c}{$1-10$ days of age $(\mathrm{g})$} \\
\cline { 2 - 4 } & BWG & FI & FCR \\
\hline Control & $199.09^{\mathrm{bc}}$ & 251.25 & $1.26^{\mathrm{ab}}$ \\
Sham group & $196.03^{\mathrm{c}}$ & 255.78 & $1.30^{\mathrm{a}}$ \\
Gln 10 mg & $206.21^{\mathrm{ab}}$ & 251.98 & $1.22^{\mathrm{abc}}$ \\
Gln 20 mg & $207.87^{\mathrm{a}}$ & 245.00 & $1.17^{\mathrm{bc}}$ \\
Gln 30 mg & $209.98^{\mathrm{a}}$ & 246.97 & $1.17^{\mathrm{bc}}$ \\
Gln 40 mg & $206.49^{\mathrm{ab}}$ & 250.14 & $1.21^{\mathrm{abc}}$ \\
Gln 50 mg & $213.70^{\mathrm{a}}$ & 243.24 & $1.14^{\mathrm{c}}$ \\
SEM & 2.53 & 6.49 & 0.03 \\
$P$ Value & 0.0010 & 0.8358 & 0.0237 \\
\hline a-c Averages in a column with different superscript letters are \\
significantly different.
\end{tabular}

\subsection{Carcass measurements}

On day 42, two broilers per pen were selected (close to the mean weight of each cage), weighed and killed by cervical dislocation, and then the abdominal cavity was opened. Weights of the eviscerated hot carcass, breast muscle, thigh, liver, heart, gizzard, abdominal fat, intestine, pancreas and spleen were recorded and the corresponding percentages $(\%$ of live body weight) were calculated.

\subsection{Statistical analysis}

Analyses of variance were performed using the GLM procedure of SAS Institute Inc. (2005) as a completely randomized design. Results are presented as mean \pm SEM. The significantly different treatment means were investigated using Duncan's new multiple rang test. Differences were considered significant when $p<0 / 05$. 
Table 4. Effects of IOF of Gln on body weight gain (BWG), food intake (FI) and feed conversion ratio (FCR) of broilers to 1126 days of age.

\begin{tabular}{lrrr}
\hline \multirow{2}{*}{ Groups } & \multicolumn{3}{c}{$11-26$ days of age $(\mathrm{g})$} \\
\cline { 2 - 4 } & BWG & FI & FCR \\
\hline Control & $647.74^{\mathrm{bc}}$ & 915.24 & $1.41^{\mathrm{a}}$ \\
Sham group & $639.75^{\mathrm{c}}$ & 917.80 & $1.43^{\mathrm{a}}$ \\
Gln 10 mg & $673.12^{\mathrm{ab}}$ & 909.36 & $1.35^{\mathrm{bc}}$ \\
Gln 20 mg & $669.22^{\mathrm{abc}}$ & 907.66 & $1.35^{\mathrm{b}}$ \\
Gln 30 mg & $686.50^{\mathrm{a}}$ & 904.98 & $1.31^{\mathrm{bc}}$ \\
Gln 40 mg & $679.96^{\mathrm{a}}$ & 892.87 & $1.31^{\mathrm{bc}}$ \\
Gln 50 mg & $692.19^{\mathrm{a}}$ & 895.13 & $1.29^{\mathrm{c}}$ \\
SEM & 9.68 & 8.23 & 0.01 \\
$P$ Value & 0.0074 & 0.2981 & 0.0001 \\
\hline a-c Averages in a column with different superscript letters are \\
significantly different.
\end{tabular}

Table 5. Effects of IOF of Gln on body weight gain (BWG), food intake (FI) and feed conversion ratio (FCR) of broilers to 2742 days of age.

\begin{tabular}{lrrr}
\hline \multirow{2}{*}{ Groups } & \multicolumn{3}{c}{$27-42$ days of age $(\mathrm{g})$} \\
\cline { 2 - 4 } & BWG & FI & FCR \\
\hline Control & $1403.42^{\mathrm{b}}$ & 3152.50 & $2.24^{\mathrm{a}}$ \\
Sham group & $1397.97^{\mathrm{b}}$ & 3143.50 & $2.24^{\mathrm{a}}$ \\
Gln 10 mg & $1452.57^{\mathrm{a}}$ & 3139.52 & $2.16^{\mathrm{b}}$ \\
Gln 20 mg & $1448.25^{\mathrm{a}}$ & 3135.03 & $2.16^{\mathrm{b}}$ \\
Gln 30 mg & $1455.59^{\mathrm{a}}$ & 3124.25 & $2.14^{\mathrm{bc}}$ \\
Gln 40 mg & $1472.97^{\mathrm{a}}$ & 3115.05 & $2.11^{\mathrm{bc}}$ \\
Gln 50 mg & $1483.72^{\mathrm{a}}$ & 3124.99 & $2.10^{\mathrm{c}}$ \\
SEM & 11.41 & 11.54 & 0.01 \\
$P$ Value & 0.0001 & 0.3229 & 0.0001 \\
\hline a-c Averages in a column with different superscript letters are \\
significantly different.
\end{tabular}

\section{Results}

The effects of IOF with different levels of Gln solutions at 7 days of incubation on hatchability and weights of newly hatched chickens are presented in Table 2. IOF with Gln and deionized water reduced the hatchability compared with the control group (not injection eggs). But, the mean body weights of newly hatched chickens injected by Gln were increased more than the control groups. IOF of Gln improved body weight gain and feed conversion ratio through the whole experimental period but feed intake was not significantly altered (Tables 3-6).

As seen in Tables 7 and 8, villus height, villus width and crypt depth in jejunum were significantly increased in chickens treated in ovo by Gln compared to the non-injected and sham controls in newly hatched and 10-day old chickens.
Table 6. Effects of IOF of Gln on body weight gain (BWG), food intake (FI) and feed conversion ratio (FCR) of broilers to $1-42$ days of age.

\begin{tabular}{lrrr}
\hline \multirow{2}{*}{ Groups } & \multicolumn{3}{c}{$1-42$ days of age (g) } \\
\cline { 2 - 4 } & BWG & FI & FCR \\
\hline Control & $2250.26^{\mathrm{c}}$ & 4318.99 & $1.91^{\mathrm{a}}$ \\
Sham group & $2233.74^{\mathrm{c}}$ & 4317.08 & $1.93^{\mathrm{a}}$ \\
Gln 10 mg & $2331.91^{\mathrm{ab}}$ & 4300.86 & $1.84^{\mathrm{b}}$ \\
Gln 20 mg & $2325.34^{\mathrm{b}}$ & 4287.69 & $1.84^{\mathrm{b}}$ \\
Gln 30 mg & $2352.08^{\mathrm{ab}}$ & 4276.20 & $1.81^{\mathrm{bc}}$ \\
Gln 40 mg & $2359.43^{\mathrm{ab}}$ & 4258.06 & $1.80^{\mathrm{bc}}$ \\
Gln 50 mg & $2389.61^{\mathrm{a}}$ & 4263.36 & $1.78^{\mathrm{c}}$ \\
SEM & 19.69 & 22.60 & 0.01 \\
$P$ Value & 0.0001 & 0.3558 & 0.0001 \\
\hline a-c Averages in a column with different superscript letters are \\
significantly different.
\end{tabular}

Table 7. Effects of IOF of Gln on villus height, villus width and crypt depth in jejunum of newly hatched chickens.

\begin{tabular}{lrrr}
\hline Groups & $\begin{array}{r}\text { Villus } \\
\text { height }(\mu \mathrm{m})\end{array}$ & $\begin{array}{r}\text { Villus } \\
\text { width }(\mu \mathrm{m})\end{array}$ & $\begin{array}{r}\text { Crypt } \\
\text { depth }(\mu \mathrm{m})\end{array}$ \\
\hline Control & $342.24^{\mathrm{ef}}$ & $49^{\mathrm{bc}}$ & $50.50^{\mathrm{d}}$ \\
Sham group & $338.19^{\mathrm{f}}$ & $48^{\mathrm{c}}$ & $49.25^{\mathrm{d}}$ \\
Gln 10 mg & $357.89^{\mathrm{bcd}}$ & $55^{\mathrm{ab}}$ & $60.00^{\mathrm{bc}}$ \\
Gln 20 mg & $355.48^{\mathrm{bcde}}$ & $58^{\mathrm{a}}$ & $59.00^{\mathrm{c}}$ \\
Gln 30 mg & $352.25^{\mathrm{cde}}$ & $56^{\mathrm{a}}$ & $65.25^{\mathrm{abc}}$ \\
Gln 40 mg & $360.49^{\mathrm{ab}}$ & $59^{\mathrm{a}}$ & $68.00^{\mathrm{ab}}$ \\
Gln 50 mg & $372.07^{\mathrm{a}}$ & $60^{\mathrm{a}}$ & $70.00^{\mathrm{a}}$ \\
SEM & 4.37 & 2.13 & 2.71 \\
$P$ Value & 0.0001 & 0.0012 & 0.0001 \\
\hline
\end{tabular}

${ }^{\mathrm{a}-\mathrm{e}}$ Averages in a column with different superscript letters are significantly different.

On the 42nd day, weights of the carcass, breast, thigh and gizzard were also significantly increased in broilers from injected eggs with Gln compared to the control groups ( $p<$ 0.05 ); the highest value was observed in the group receiving $50 \mathrm{mg}$ Gln. By contrast, the liver, heart, abdominal fat, intestine, pancreas and spleen weights were not significantly altered in broilers from Gln treated eggs (Tables 9, 10).

\section{Discussion}

Concerning hatchability, Uni et al. (2005) showed that the positive effects of IOF at late-term chicken embryos may include increased hatchability. On the other hand, Pedroso et al. (2006a) reported that IOF of Gln in the amniotic fluid of embryos on day 18 of incubation had no significant effect on the hatchability. In parallel, Dos Santos et al. (2010) demonstrate that, IOF of $0.5 \mathrm{~mL}$ of a $10 \%$ Gln solution did not affect hatching of newly hatched chickens. In contrast, Ohta 
Table 8. Effects of IOF of Gln on villus height, villus width and crypt depth in jejunum of broilers when they were 10-days old.

\begin{tabular}{lrrr}
\hline Groups & $\begin{array}{r}\text { Villus } \\
\text { height }(\mu \mathrm{m})\end{array}$ & $\begin{array}{r}\text { Villus } \\
\text { width }(\mu \mathrm{m})\end{array}$ & $\begin{array}{r}\text { Crypt } \\
\text { depth }(\mu \mathrm{m})\end{array}$ \\
\hline Control & $656.25^{\mathrm{c}}$ & $139.00^{\mathrm{d}}$ & $86^{\mathrm{b}}$ \\
Sham group & $647.50^{\mathrm{c}}$ & $141.75^{\mathrm{cd}}$ & $85^{\mathrm{b}}$ \\
Gln 10 mg & $677.00^{\mathrm{b}}$ & $152.75^{\mathrm{abc}}$ & $94^{\mathrm{a}}$ \\
Gln 20 mg & $687.50^{\mathrm{ab}}$ & $162.50^{\mathrm{a}}$ & $98^{\mathrm{a}}$ \\
Gln 30 mg & $684.25^{\mathrm{ab}}$ & $151.75^{\mathrm{abc}}$ & $97^{\mathrm{a}}$ \\
Gln 40 mg & $691.00^{\mathrm{ab}}$ & $155.75^{\mathrm{ab}}$ & $96^{\mathrm{a}}$ \\
Gln 50 mg & $702.75^{\mathrm{a}}$ & $158.50^{\mathrm{a}}$ & $95^{\mathrm{a}}$ \\
SEM & 6.99 & 3.70 & 1.87 \\
$P$ Value & 0.0001 & 0.0009 & 0.0001
\end{tabular}

a-e Averages in a column with different superscript letters are significantly different.

et al. (1999) showed that the hatchability was significantly reduced when injecting amino acids at day 0 of incubation. Chen et al. (2010) stated that hatchability of control, sources and maltose (DS), L-alanyl-L-glutamine (Ala-Gln), Sucrose, maltose and L-alanyl-L-glutamine (DS + Ala-Gln), groups were $85,65,70$ and $82 \%$ respectively. Moreover, DS and Ala-Gln decreased the hatchability by 24 and $18 \%(p<$ 0.01), respectively. In an experiment by Chen et al. (2010), the $\mathrm{pH}$ of all the injection solution was adjusted to about 6.8 and the osmolarity was 154, 2264 and $30 \mathrm{mOsm}$ for DS, Ala-Gln and DS + Ala-Gln solution respectively. These researchers showed that decreasing in hatchability was due to varied osmolarity of the injection. Previous work demonstrated that the osmolarity of injection solution was a critical factor in affecting the hatchability of the chick (Ferket et al., 2005). In parallel, Pedroso et al. (2006b) also found that decreased hatchability was observed when chick embryos received glucose in ovo injection at 16 days of incubation. The significant difference in hatchability among the in ovo injected groups indicated that nutrient specificity might result in the differing response of embryos. According to the US Patent (6592878) of Uni and Ferket (2003) the importance of the osmolarity of the in ovo feeding solution on hatchability of chicks was illustrated. Acceptable hatchability of chicks was observed when eggs were injected with solutions having an osmolarity ranging below $800 \mathrm{mOsm}$ with an optimum hatchability observed at about 400-600 mOsm. Unacceptable hatching rates were observed when the in ovo feeding solution exceeded $800 \mathrm{mOsm}$. In the present study osmolality of all the injection of solutions was adjusted to about 450 mOsm. Thus, osmolarity could not be the reason for the decreasing of the hatchability. This is consistent with the results obtained in the present study, in which the injection of different levels of Gln and deionized water caused significant decrease in the hatchability. Probably the reducing hatchability was due to the IOF into the albumin. One of the possible reasons for the decreasing rate of hatching is the allergic cav-
Table 9. Effects of IOF of Gln on weight of carcass, breast and thigh of broiler chickens when they were 42-days old (based on percentage of live body weight).

\begin{tabular}{lrrr}
\hline Groups & Carcass $(\%)$ & Breast (\%) & Thigh $(\%)$ \\
\hline Control & $67.56^{\mathrm{d}}$ & $23.92^{\mathrm{c}}$ & $19.96^{\mathrm{c}}$ \\
Sham group & $67.71^{\mathrm{d}}$ & $24.21^{\mathrm{c}}$ & $19.82^{\mathrm{c}}$ \\
Gln 10 mg & $68.58^{\mathrm{c}}$ & $24.94^{\mathrm{b}}$ & $20.68^{\mathrm{b}}$ \\
Gln 20 mg & $68.48^{\mathrm{c}}$ & $24.89^{\mathrm{b}}$ & $20.64^{\mathrm{b}}$ \\
Gln 30 mg & $68.71^{\mathrm{bc}}$ & $25.55^{\mathrm{a}}$ & $21.35^{\mathrm{a}}$ \\
Gln 40 mg & $68.97^{\mathrm{ab}}$ & $25.78^{\mathrm{a}}$ & $21.48^{\mathrm{a}}$ \\
Gln 50 mg & $69.18^{\mathrm{a}}$ & $25.86^{\mathrm{a}}$ & $21.61^{\mathrm{a}}$ \\
SEM & 0.08 & 0.11 & 0.09 \\
$P$ Value & 0.0001 & 0.0001 & 0.0001 \\
\hline
\end{tabular}

${ }^{a-d}$ Averages in a column with different superscript letters are significantly different.

ity under the air sac causing the respiration of developing embryo to stop and die. Heiblum et al. (2001) showed that IOF of glucocorticoid at day 7 of incubation resulted in $35 \%$ decline of rate of hatching. Also, Salmanzadeh et al. (2012) observed lower hatchability when 7-day old broiler embryos were injected with glucose and magnesium. Thus, it seems that any IOF at early embryonic life can be harmful for the internal environment susceptibility and have negative effects on rate of hatching. This effect may largely independent depend on injected Gln effect.

Data of this study showed that the IOF of Gln into the albumin can be seen as an effective tool to improve the mean body weights of newly hatched chickens. Previous studies showed that to stimulate the development of the chick embryo is an important factor in increasing the weight of newly hatched chickens (Tako et al., 2004a; Uni and Ferket, 2004; Uni et al., 2005; Smirnov et al., 2006). Al-Murrani (1982) showed that IOF of amino acid into fertile goose eggs at day 7 of incubation increased the weight of newly hatched geese. In turkeys, Foye et al. (2006) observed that in ovo injection of egg white protein at day 23 of incubation increased hatching weight. Ohta et al. (2001) reported that IOF of amino acids into the air cell of 7-day old embryos improved utilization of amino acid by the embryo and consequently increased hatching weight. On the other hand, Dos Santos et al. (2010) showed that IOF with $10 \%$ Gln at 18 days of incubation did not influence hatch weight. In another study, Chen et al. (2009) showed that in ovo administration of Gln and carbohydrates in combination in the duck did not affect the body weight at 25 days of incubation, weight of hatch and weight of ducks on day 3 post-hatching. According to the past studies and our present observations, the late-term embryo and neonatal chicken depends on gluconeogenesis from amino acids, resulting in the depletion of muscle protein reserves and the reduction of hatching weight. To reduce the depletion of muscle protein, we carried out IOF Gln into albumen prior to hatching, which would support the en- 
Table 10. Effects of IOF of Gln on weight of heart, liver, gizzard, abdominal fat, intestine, pancreas and spleen of broiler chickens when they were 42-days old (based on percentage of live body weight).

\begin{tabular}{lrrrrrrr}
\hline Groups & Heart (\%) & Liver $(\%)$ & Gizzard (\%) & Abdominal fat (\%) & Intestine(\%) & Pancreas (\%) & Spleen (\%) \\
\hline Control & 0.58 & 2.09 & $1.70^{\mathrm{b}}$ & 2.13 & 4.49 & 0.143 & 0.126 \\
Sham group & 0.60 & 2.11 & $1.69^{\mathrm{b}}$ & 2.16 & 4.45 & 0.148 & 0.121 \\
Gln 10 mg & 0.64 & 2.13 & $2.01^{\mathrm{a}}$ & 2.23 & 4.68 & 0.158 & 0.129 \\
Gln 20 mg & 0.64 & 2.18 & $1.99^{\mathrm{a}}$ & 2.34 & 4.62 & 0.156 & 0.133 \\
Gln 30 mg & 0.68 & 2.24 & $1.96^{\mathrm{a}}$ & 2.32 & 4.85 & 0.160 & 0.135 \\
Gln 40 mg & 0.69 & 2.18 & $2.09^{\mathrm{a}}$ & 2.36 & 4.92 & 0.164 & 0.141 \\
Gln 50 mg & 0.73 & 2.21 & $2.11^{\mathrm{a}}$ & 2.42 & 5.04 & 0.170 & 0.142 \\
SEM & 0.06 & 0.09 & 0.05 & 0.08 & 0.16 & 0.009 & 0.004 \\
$P$ Value & 0.7562 & 0.9168 & 0.0001 & 0.1251 & 0.2058 & 0.6085 & 0.4787 \\
\hline
\end{tabular}

a-b Averages in a column with different superscript letters are significantly different.

ergy status of the hatching by moderating the use of muscle that consequently increases body weight at hatching. In addition, Foye et al. (2006) showed that the supply of nutrient by IOF improved avian energy status, which spared energy used for metabolism and, consequently, increased postnatal performance. Today, whole embryonic life is almost $35 \%$ of the productive life of broilers. Thus, to stimulate the development of the chick embryo is an important factor to increase the weight of newly hatched chicks. Also, previous studies showed that weight of newly hatched chickens is a major predictor for marketing weight in modern broilers. Wilson (1991) stated that each $1 \mathrm{~g}$ of improvement in weight of newly hatched chickens leads to $8-13 \mathrm{~g}$ of improvement in body weight at marketing. In this study we demonstrate that a $1 \mathrm{~g}$ difference in weight of newly hatched chickens due to IOF resulted in 109-130 g increase in body weight at day 42 .

Based on the results of this study, the growth performance of broiler chickens linearly increased with the improved development of the gastrointestinal tract. Thus, improved growth performance was dependent upon the development of the gastrointestinal tract and IOF of Gln used. Previous studies showed that the dietary supplementation with Gln stimulates the intestine development and improved the growth performance of turkey poults first week after hatch (Yi et al., 2001), weanling pigs (Kitt et al., 2002), broilers (Bartell and Batal, 2007) and Japanese quails (Salmanzadeh and Shahryar, 2013b).

It is well demonstrated that Gln appears to be a conditionally essential amino acid nutrient as exogenous Gln can be a potential candidate in improving intestinal morphology and digestive function (Alverdy et al., 1992; Helton et al., 1990; Shizuka et al., 1990). On the other hand, from the conclusions above, it is concluded that the increase in intestinal villus height reported in animals fed with Gln supplemented diets may explain the improvement in growth performance. Therefore, the increased villus height may amplify nutrient absorption and utilization of nutrients leading to improved growth performance of broiler chickens. On the contrary, Chen et al. (2009) reported that body weights measured at the 25th day of incubation, at hatch (Day 0), and at the 3rd day post-hatching were not significantly modified in ducks treated in ovo with Gln, whereas IOF of Gln improved small intestine development and body weight than the control ducks when they were 7-days old.

In the present study, the relative weights of carcass, breast, thigh and gizzard were also significantly improved in broiler chickens injected with Gln. Chen et al. (2009) demonstrated that the in ovo injection of Gln at day 21 of incubation improved breast weight of ducks at $25 \mathrm{~d}$ of incubation until day 7 of post-hatch, whereas gizzard, proventriculus and liver weight were not significantly altered. Salmanzadeh and Shahryar (2013b) showed that dietary Gln supplementation $\left(0,20,30,40\right.$ and $50 \mathrm{mg} \mathrm{kg}^{-1}$ of diet) significantly increased the relative weights of carcass and breast compared to the control quails whereas liver and gizzard weights were not significantly modified.

Dai et al. (2009) demonstrated that dietary Gln addition ( 5 and $10 \mathrm{~g} \mathrm{~kg}^{-1}$ ) improved growth performance and carcass traits of broilers. Furthermore, in another study, increases in carcass weight and relative weight of breast and thigh were also significantly improved in broilers supplemented with Gln at $5 \mathrm{~g} \mathrm{~kg}^{-1}$ of diet (Dai et al., 2011).

\section{Conclusions}

As a conclusion, IOF of Gln into broiler breeder eggs stimulated development of gastrointestinal tract and consequently, improved the growth performance and carcass characteristics whereas hatchability significantly depressed in all injected eggs compared to the not injected ones.

Author contributions. M. Salmanzadeh carried out the experiment and prepared the manuscript. Y. Ebrahimnezhad, H. Aghdam Shahryar, J. Ghiasi Ghaleh-Kandi designed and coordinated the experiment and helped to modify the manuscript. 
Acknowledgements. This article is a part of $\mathrm{PhD}$ thesis in animal science, Islamic Azad University, Shabestar Branch (thesis supervisors: Y. Ebrahimnezhad and H. A. Shahryar, consulting advisor: J. Ghiasi Ghaleh-Kandi). Also, the authors have highly appreciated the cooperation of Saeid Ashrafi and Ayob heshmati sis for taking care of birds during the experiment period and helping in the process of experimental work.

Edited by: S. Maak

Reviewed by: two anonymous referees

\section{References}

Al-Murrani, W. K.: Effect of injecting amino acids into the egg on embryonic and subsequent growth in the domestic fowl, Br. Poult. Sci., 23, 171-174, 1982.

Alverdy, J. A., Aoys, E., Weiss-Carrington, P., and Burke, D. A: The effect of glutamine-enriched TPN on gut immune cellularity, J. Surg. Res., 52, 34-38, 1992.

Andrews, F. J. and Griffiths, R. D.: Glutamine: essential for immune nutrition in the critically ill, Br. J. Nutr., 1, 3-8, 2002.

Bartell, S. M. and Batal, A. B.: The effect of supplemental glutamine on growth performance, development of the gastrointestinal tract, and humoral immune response of broilers, Poult. Sci., 86, 1940-1947, 2007.

Chen, W., Wang, R., Wan, H. F., Xiong, X. L., Peng, P., and Peng, J.: Influence of in ovo injection of glutamine and carbohydrates on digestive organs and pectoralis muscle mass in the duck, $\mathrm{Br}$. Poult. Sci., 50, 436-442, 2009.

Dai, S. F., Wang, L. K., Wen, A. Y., and Wang, L. X.: Protection of glutamine supplementation to performance, intestinal enzyme activity and morphosis in broiler under heat stress, J. Chin. Cereal. Oils Assoc., 24, 103-107, 2009.

Dai, S. F., Gao, F., Zhang, W. H., Song, S. X., Xu, X. L., and Zhou, G. H.: Effects of dietary glutamine and gamma-aminobutyric acid on performance, carcass characteristics and serum parameters in broilers under circular heat stress, Anim. Feed. Sci. Technol., 168, 51-60, 2011.

Dong, X. Y., Jiang, Y. J., Wang, M. Q., Wang, Y. M., and Zou, X.T.: Effects of in ovo feeding of carbohydrates on hatchability, body weight, and energy status in domestic pigeons, Poult. Sci., 92, 2118-2123, 2013.

Dos Santos, T. T., Corzo, A., Kidd, M. T., McDaniel, C. D., Torres Filho, R. A., and Araújo, L. F.: Influence of in ovo inoculation with various nutrients and egg size on broiler performance, J. Appl. Poult. Res., 19, 1-12, 2010.

Ferket, P., De, J., Ghane, A., and Uni, Z.: Effects of in ovo feeding solution osmolality on hatching turkey, Poult. Sci., 84, 117-121, 2005.

Foye, O. T., Uni, Z., and Ferket, P. R.: Effect of in ovo feeding egg white protein, $\beta$-hydroxy- $\beta$-methylbutyrate, and carbohydrateson glycogen status and neonatal growth of turkeys, Poult. Sci., 85, 1185-1192, 2006.

Heiblum, R., Arnon, E., Chazan, G., Robinzon, B., Gvaryahu, G., and Snapir, N.: Glucocorticoid administration during incubation: Embryo mortality and post-hatch growth in chickens, Poult. Sci., 80, 1357-1363, 2001.

Helton, W. S., Jacobs, D. O., Bonner-Weir, S., Bueno, R., Smith, R. J., and Wilmore, D. W.: Effects of glutamine-enriched parenteral nutrition on the exocrine pancreas, J. Parenter. Enteral. Nutr., 14, 344-352, 1990.

Jazideh, F., Farhoomand, P., Daneshyar, M., and Najafi, G.: The effects of dietary glutamine supplementation on growth performance and intestinal morphology of broiler chickens reared under hot conditions, Turk. J. Vet. Anim. Sci., 38, 264-270, 2014.

Kitt, S. J., Miller, P. S., Lewis, A. J., and Fischer, R. L.: Effects of glutamine on growth performance and small intestine villus height in weanling pigs, Nebraska Swine Report, 82, 29-32, 2002.

Nowaczewski, S., Kontecka, H., and Krystianiak, S.: Effect of in ovo injection of vitamin $\mathrm{C}$ during incubation on hatchability of chickens and ducks, Folia Biologica (Kraków), 60, 93-97, 2012.

Ohta, Y., Tsushima, N., Koide, K., Kidd, M. T., and Ishibashi, T.: Effect of amino acid injection in broiler breeder eggs on embryonic growth and hatchability of chicks, Poult. Sci., 78, 14931498, 1999.

Ohta, Y., Kidd, M. T., and Ishibashi, T.: Embryo growth and amino acid concentration profiles of broiler breeder eggs, embryos, and chicks after in ovo administration of amino acids, Poult. Sci., 80, 1430-1436, 2001.

Ohta, Y., Yoshida, T., and Tsushima, T.: Comparison between broilers and layers for growth and protein use by embryos, Poult. Sci., 83, 783-787, 2004.

Pedroso, A. A., Chaves, L. S., Café, M. B., Leandro, N. S. M, Stringhini, J. H., and Menten, J. F. M.: Glutamine as broilers embryos nutrient, Braz. J. Avian. Sci. Camp., 8, 43-49, 2006 .

Pedroso, A. A., Chaves, L. S., Lopes, K. L. D. M., Leandro, N. S. M., Café, M. B., and Stringhini, J. H.: Nutrient inoculation in eggs from heavy breeders, Rev. Bras. Zootecn., 35, 2018-2026, 2006 b.

Salmanzadeh, M.: The effects of in-ovo injection of glucose on hatchability, hatching weight and subsequent performance of newly-hatched chicks, Braz. J. Poult. Sci., 14, 137-140, 2011.

Salmanzadeh, M. and Shahryar, H. A.: Effects of dietary supplementation with glutamine on growth performance, small intestinal morphology and carcass traits in turkey poults under heat stress, Revue. Méd. Vét., 164, 476-480, $2013 \mathrm{a}$.

Salmanzadeh, M. and Shahryar, H. A.: Effects of dietary glutamine addition on growth performance, carcass characteristics and development of the gastrointestinal tract in Japanese quails, Revue. Méd. Vét., 164, 471-475, $2013 b$.

Salmanzadeh, M., Ebrahimnezhad, Y., Shahryar, H. A., and Beheshti, R.: The effects of in ovo injection of glucose and magnesium in broiler breeder eggs on hatching traits, performance, carcass characteristics and blood parameters of broiler chickens, Arch. Geflügelk., 76, 277-284, 2012.

Samli, H. E., Senkoylu, N., Koc, F., Kanter, M., and Agma, A.: Effects of Enterococcus faecium and dried whey on broiler performance, guthistomorphology and microbiota, Arch. Anim. Nutr., 61, 42-49, 2007.

SAS Institute, SAS Users guide: Statistics, Version 9.12, SAS Institute Inc., Cary, NC, USA, 2005.

Shizuka, F., Vasupongsotorn, S., Kido, Y., and Kish, K.: Comparative effect of intravenously or intragastrically administered glutamine on small intestinal function of the rat, Tokushima, J. Exp. Med., 37, 49-57, 1990.

Smirnov, A., Tako, E., Ferket, P. R., and Uni, Z.: Mucin gene expression and mucin content in the chicken intestinal goblet cells 
are affected by in ovo feeding of carbohydrates, J. Poult. Sci., 85 , 669-673, 2006.

Souba, W. W.: Glutamine and cancer, Ann. Surg., 218, 715-728, 1993.

Tako, E., Ferket, P. R., and Uni, Z.: Effects of in ovo feeding of carbohydrates and $\beta$ - Hydroxy- $\beta$-Methylbutyrate on the development of chicken intestine, Poult. Sci., 83, 2023-2028, 2004a.

Tako, E., Ferket, P. R., and Uni, Z.: Changes in chicken intestinal zinc exporter mRNA expression and small intestinal functionality following intra-amniotic zinc-methionine administration, J. Nutr. Biochem., 16, 339-346, 2004b.

Touchette, K. J., Carroll, J. A., Allee, G. L., Matteri, R. L., Dyer, C. J., Beausang, L. A., and Zannelli, M. E.: Effect of spray-dried plasma and lipopolysaccharide exposure on weaned pigs: I. Effects on the immune axis of weaned pigs, J. Anim. Sci., 80, 494501, 2002.

Uni, Z. and Ferket, P. R.: Enhancement of development of oviparous species by in ovo feeding, US Regular Patent US 6, 592, 878, 2003.
Uni, Z. and Ferket, R. P.: Methods for early nutrition and their potential, World's Poult. Sci. J., 60, 101-111, 2004.

Uni, Z., Ferket, P. R., Tako, E., and Kedar, O.: In ovo feeding improves energy status of lateterm chicken embryos, Poult. Sci., 84, 764-770, 2005,

Wilson, J. H.: Bone strength of caged layers as affected by dietary calcium and phosphorus concentrations, reconditioning, and ash content, Br. Poult. Sci., 32, 501-508, 1991.

Yi, G. F., Allee, G. L., Spencer, J. D., Frank, J. W., and Gaines, A. M.: Impact of glutamine, menhaden fish meal and spray-dried plasma on the growth performance and intestinal morphology of turkey poults, Poult. Sci., 80, 201-204, 2001.

Yi, G. F., Allee, G. L., Knight, C. D., and Dibner, J. J.: Impact of glutamine and oasis hatchling supplement on growth performance, small intestinal morphology, and immune response of broilers vaccinated and challenged with Eimeria maxima, Poult. Sci., 84, 283-293, 2005. 